\title{
Factor Structure of the Coping Inventory for Stressful Situations (CISS) in Japanese Workers
}

\author{
Yukihiro Takagishi, Masatsugu Sakata, Toshinori Kitamura \\ Department of Psychology, Kansai University of International Studies, Miki, Japan \\ Email: takagishi@h9.dion.ne.jp
}

Received 23 July 2014; revised 19 August 2014; accepted 15 September 2014

Copyright (C) 2014 by authors and Scientific Research Publishing Inc.

This work is licensed under the Creative Commons Attribution International License (CC BY).

http://creativecommons.org/licenses/by/4.0/

cC) (i) Open Access

\begin{abstract}
Different models of factor structure were proposed for the Coping Inventory for Stressful Situations (CISS) as a measure of coping style. This study confirmed psychometric properties and stability of the factor structure and differences among models for various age groups. The CISS of the Japanese version and the Hopkins Symptom Checklist (HSCL) were administered to a sample of 781 Japanese workers. Using factor analysis, three-, four-, and five-factor models were examined. Simultaneous multiple-group analysis was conducted using samples of 568 workers and 507 students. The five-factor model was more robust than the original three- and four-factor models. Reliabilities and applicability for a wide age range were confirmed. In terms of predictive validity, symptoms of somatization, obsessive-compulsiveness, interpersonal sensitivity, depression, and anxiety were positively related with Rumination coping.
\end{abstract}

\section{Keywords}

Component, Coping, Factor Model, Predictive Validity, Multiple Age Groups

\section{Introduction}

While the notion of coping has long been recognized in several fields of psychology, it is still a complex issue. In many investigations, the concept of coping is used differently by various theorists, each of whom applied different terms to descriptions of behavior. Some focus on patterns of behavioral response to stressful situations, while others emphasize dispositional aspects of personalities. The former approach is called a "contextual approach," while the latter is called a "stylistic or dispositional approach" (Moos \& Holahan, 2003).

Stress-appraisal-coping model (Lazarus \& Folkman, 1984) is a typical contextual approach. They defined 
coping as "constantly changing cognitive and behavioral efforts to manage specific external and/or internal demands that are appraised as taxing or exceeding the resources of the person” (p. 141). In this model, coping is considered to reflect a response to specific stressors rather than a pattern of an intrinsic personality trait. Therefore, if one's appraisal is emotionally negative, responses would be to reduce the negative emotion. However, since there are individual differences in interpreting situations, according to this model behavior prediction is difficult.

In contrast to a contextual approach, a stylistic or dispositional approach considers that stable and enduring personality, attitudinal and cognitive characteristics provide the most important part of the psychological context for coping (Moos \& Holahan, 2003). This approach is based on a classical notion that people act on specific and characteristic styles of coping behavior when confronted with stressful situations (Cosway, Endler, Sadler, \& Deary, 2000). Therefore, the approach is not restricted to stressful events, but concerns qualities of personality, and is not based on assumptions regarding the cognitive and emotional components of behavior.

Several measurements have been developed in each perspective. The Ways of Coping Questionnaire (WCQ: Folkman \& Lazarus, 1988) was constructed from the contextual approach. With eight subscales in this questionnaire, different styles of coping are grouped into two categories, emotion-focused and problem-focused. In the latter, attention is paid directly to the problem which is to be solved. On the other hand, in the former view, attention is paid to regulate emotional distress including avoidance.

What coping strategy was chosen depends partly on evaluation of whether the situation will change. If situation is as unchangeable, emotion-focused coping is more likely to be chosen while problem-focused coping is more likely if the situation is viewed changeable (Folkman \& Lazarus, 1985). The eight factors of the WCQ, however, are not stable depending on sample and stressors (Van Heck \& De Ridder, 2001). Several conclusions were drawn about the effectiveness of each strategy depending on the stressor's characteristics, controllability, and the duration of coping efforts when dealing with it (Lazarus, 1999).

When coping was conceptualized from a dispositional approach, later coping measurements were developed based on trait assessment. Unfortunately, some measurement devices have methodological drawbacks such as low reliability and unstable factor structure (Skinner, Edge, Altman, \& Sherwood, 2003). Nevertheless, the Coping Inventory for Stressful Situations (CISS: Endler \& Parker, 1990) is a more sophisticated measure of coping dispositions with excellent psychometric properties. It asks the frequency of a testee's behaviors listed on the questionnaire when under stressful. The CISS assesses task-oriented, emotion-oriented, and avoidanceoriented coping styles, which are proposed to be further categorized as two factors: Distraction and Social Diversion by Endler and Parker (1994). The robustness of the CISS as a coping measure has been confirmed by previous researchers and the assessment coping both as a personality feature and response to a specific situation (Endler \& Parker, 1994).

Although a three-factor structure was proposed originally (Endler \& Parker, 1990), other models of the factor structure have been proposed. Cosway, Endler, Sadler, and Deary (2000) proposed a four-factor model by dividing all items into Task- and Non-task-oriented items. Non-task-oriented items were further divided into Emotion-oriented and Avoidance-oriented items. Avoidance-oriented items were further separated into Distraction and Social Diversion items. McWilliams, Cox, and Enns (2003) suggested a different four-factor model, including Task, Emotion, Social, and Distraction factors. While each factor in McWilliams, et al.'s four-factor model were considered independent, emotion-focused coping and avoidance-oriented coping in Cosway's four-factor model were categorized as having the same factors. Rafnsson, Smari, Windle, Mears, \& Endler (2006) examined the difference between three and four-factor models (Avoidance was divided into items of Distraction and Social Diversion) with a sample of 1251 Iceland's adolescents. They concluded that the CISS could be used in both the three- and four-factor models. Sakata, Takagishi, and Kitamura (2013) have recently proposed a five-factor model using responses collected from a sample of student age dividing all items into Action-oriented and Emotion-oriented items. Action-oriented items represented two factors, Task Solution and Social Diversion, and Emotion-oriented items include three factors, Rumination, Aggression, and Distraction. Although the factor structure of this model was robust compared with other models, it should be noted that the sample was limited to range in age from 18 to 25 . One purpose of this study was to confirm the factor structure of the CISS by using a broad range of age, sample of workers representing.

The CISS has been reported to have acceptable predictive validity. For example, there are associations among the subscales, especially Emotion-oriented coping and also with scores of depression and anxiety in the General Health Questionnaire (GHQ-28) (Cosway, Endler, Sadler, \& Deary, 2000; Endler, Parker, \& Butcher, 1993). 
However, few researchers have examined the relations of coping styles with other symptoms than depression and anxiety, such as physical symptoms. A second purpose of this study was to elucidate the relations of coping styles with different stress symptoms.

As Endler and Parker (1990) noted, there is empirical research on sex differences in CISS scores. Cosway et al. (2000) reported that women scored significantly higher than men on all factors, Emotion-oriented, Avoidance-oriented, Distraction, and Social Diversion except the Task-oriented coping factor, for which the women's score was not significantly higher. Endler and Parker (1994) reported similar results, specifically, that the Emotion-oriented and Avoidance-oriented coping scales scores of women were higher than those of men, and only college men scored higher than college women on the Task-oriented coping scale. Higgins and Endler (1995) found that there was negative relation between Task-oriented coping and anguish only in men. The present study also examined sex differences in the relations of coping behavior with stress symptoms.

This study (1) compared different models of the factor structure of the CISS using a broad-age of workers, (2) examined the validity of each set of subscales derived from the established factor structure in its predictive ability of different types of stress symptoms, and (3) compared the CISS factor structures of men and women.

\section{Methods}

\subsection{Participants}

The present sample ( $\mathrm{N}=939$ ) between the ages 19 and 60, was drawn from workers at two workplaces, one being a group of local public servants and the other being employees of a private dairy products company in Japan. Questionnaires were distributed to both groups two times, 767 questionnaires of 939 collected at first wave and 686 of 939 at second wave. The numbers of usable questionnaires completed and collected in the 2 surveys were 568 pairs. Participants consisted of 365 men (64.3\%) and 203 women (35.7\%). The mean age was 42.3 years $(\mathrm{SD}=10.6)$. No sex difference was found between the mean age.

An additional sample of 507 university students (Sakata et al., 2013) was used for simultaneous multiple-group analysis to examine the difference among the models in different age groups. This student sample was recruited from a project, which was conducted as a 9-wave survey prospect study. We used only the data from times 1 and 4. For the details of the recruiting procedure, refer to the study of Sakata et al. (2013).

\subsection{Measurements}

Coping style: The Coping Inventory for Stressful Situations (CISS; Endler \& Parker, 1990) of 48 items is a reliable measure of coping strategies. Respondents are asked to indicate how often they engage in various activities when they encounter stressful situations and answer each item ranging from 1; Not at all to 5; Very much. The CISS contains three 16-item scales by which assess Task-oriented coping (Task scale), Emotion-oriented coping (Emotion scale), and Avoidance-oriented coping (Avoidance scale).

Stress responses: The Hopkins Symptom Checklist (HSCL; Derogatis, Lipman, Rickels, Uhlenhuth, \& Covi, 1974) is a reliable and valid checklist evaluates psychological and somatic symptoms. Fifty-four self-rated items cover five symptomatic areas of Somatization (14 items), Obsessive-Compulsiveness (9 items), Interpersonal Sensitivity (10 items), Anxiety (8 items), and Depression (13 items). This study used the Japanese version of the checklist (Nakano \& Kitamura, 2001).

\subsection{Procedure}

This study was prospectively conducted. Questionnaires were anonymously distributed to 939 workers and collected twice at each workplace. Both first and second distribution included the HSCL and the CISS.

This study project was approved by the Ethical Committee of the Kumamoto University Graduate School of Medical Sciences (equivalent to the Institutional Review Board).

\subsection{Statistical Analyses}

A series of confirmatory factor analyses with maximum likelihood estimation were conducted to compare the three-factor (Endler \& Parker, 1990), the first four-factor (four-factor model 1; Endler \& Parker, 1994), the second four-factor (four-factor model 2; Cosway et al., 2000), and the five-factor (Sakata et al., in press) models 
of the CISS. The goodness of fit of each model was evaluated in terms of the chi-squared (CMIN), goodness-of-fit index (GFI), adjusted goodness-of-fit index (AGFI), comparative fit index (CFI), and root mean square error of approximation (RMSEA). By current criteria, a good fit would be indicated by CMIN/df $<2$, GFI $>.95$, AGFI $>.85$, CFI $>.95$, and RMSEA $<.08$ (Schermelleh-Engel, Moosbrugger, \& Müller, 2003). The Akaike Information Criterion (AIC) was used to compare the different models. If value of AIC of a model is 2 points lower than AIC value of a second model, it is regarded as the better one.

Multiple-group analysis was conducted to examine the difference in models between the occupational group and the student group. Additionally, the sex difference in the models was examined. First, a series of t-tests were conducted to examine differences between factors of CISS. Second, the four different models were compared using simultaneous multiple-group analysis: model 1, no parameters are constrained equal across groups; model 2, only the factor loadings across groups are constrained equal; model 3, factor loadings, factor variances, and factor covariances across groups are constrained equal; and model 4, factor loadings, factor variances, factor covariances, and error variances across groups are constrained equal.

The CISS measures the typical coping style of participants in stressful situations. Therefore, high reliability would be expected even when styles are measured one month later, because the original CISS proved test-retest reliability (Endler \& Parker, 1990). Suitable test-retest reliability means that there is no difficulty in answering each item of the scale over the time period. Test-retest reliability was assessed with Pearson correlation coefficients among matched items and factors, not only in the whole sample but also for sex.

Coping is the way one behaves while dealing with problematic situations related to stress responses. Thus, the relationship between coping styles and stress symptoms were prospectively examined. On the basis of the correlations in these variables, structural equation models were designed after bivariate statistical analysis. Here speculation was that time 1 symptoms would directly influence time 2 symptoms, time 1 Task oriented coping would mitigate time 2 symptoms, and other coping styles would influence time 2 symptoms.

All statistical analyses were conducted using the Statistical Package for Social Science (SPSS) version 19.0 and AMOS 19.0.

\section{Results}

\subsection{Factor Structure of CISS}

In this study, four models were examined: first, the original three-factor model was examined by its factor structure by using SEM; second, the four-factor model 1 (Endler \& Parker, 1994) then third, the four-factor model 2 (Cosway et al., 2000); and fourth, the Sakata et al.'s (2013) 5-factor model (Figure 1). The first three models did not show acceptable goodness-of-fit except for the RMSEA: GFI $=.833, .856$, and .856 , AGFI $=.807, .832$, and .832 , CFI $=.813, .842$, and .842 , RMSEA $=.070, .065$, and .065 , respectively of Table 1. The AICs were 1642.32, 1474.98, and 1474.98, respectively.

All the paths were significant $(p<.05)$ in the Sakata et al. (2013) model, using the present data and showed a good fit except for GFI and CFI (GFI $=.874$, AGFI $=.853$, CFI $=.874$, and RMSEA $=.058$, see Figure 1). The five-factor model also had the best value AIC (1284.88).

To examine whether there is a difference in the models between the worker and student samples, simultaneous multiple-group analysis was conducted. The t-tests showed that there were statistically significant differences between the worker and student samples in Task Solution, Distraction, Social Diversion, and Rumination, but not Aggression [t (1166) $=-10.95, p<.001$, t (1166) $=11.79, p<.001$, t (1166) $=8.35, p$ $<.001, \mathrm{t}(1166)=4.23, p<.001, \mathrm{t}(1166)=-.21, p>.05$, respectively]. Further, two same path diagrams were drawn to examine the heterogeneity of the corresponding path coefficients between the worker and student group, using a simultaneous multiple-group analysis.

Model 2, in which respective common factor loadings were constrained across groups, showed a better fit than model 1 (no parameters were constrained to the equal across groups; GFI $=.876$, AGFI $=.857$, CFI $=.869, \mathrm{RMSEA}=.041, \mathrm{AIC}=2611.541 ;$ and GFI $=.874, \mathrm{AGFI}=.855, \mathrm{CFI}=.868, \mathrm{RMSEA}=.041, \mathrm{AIC}=$ 2625.369, respectively), so within the same path model, there was homogeneity between the worker and student groups.

A similar result was obtained between men and women in simultaneous multiple-group analysis. The t-tests showed that there were significant differences between sample of men and women on Task Solution, Distraction, Social Diversion, and Rumination, but not Aggression [ $\mathrm{t}(566)=2.24, p<.05, \mathrm{t}(566)=-5.08, p$ 


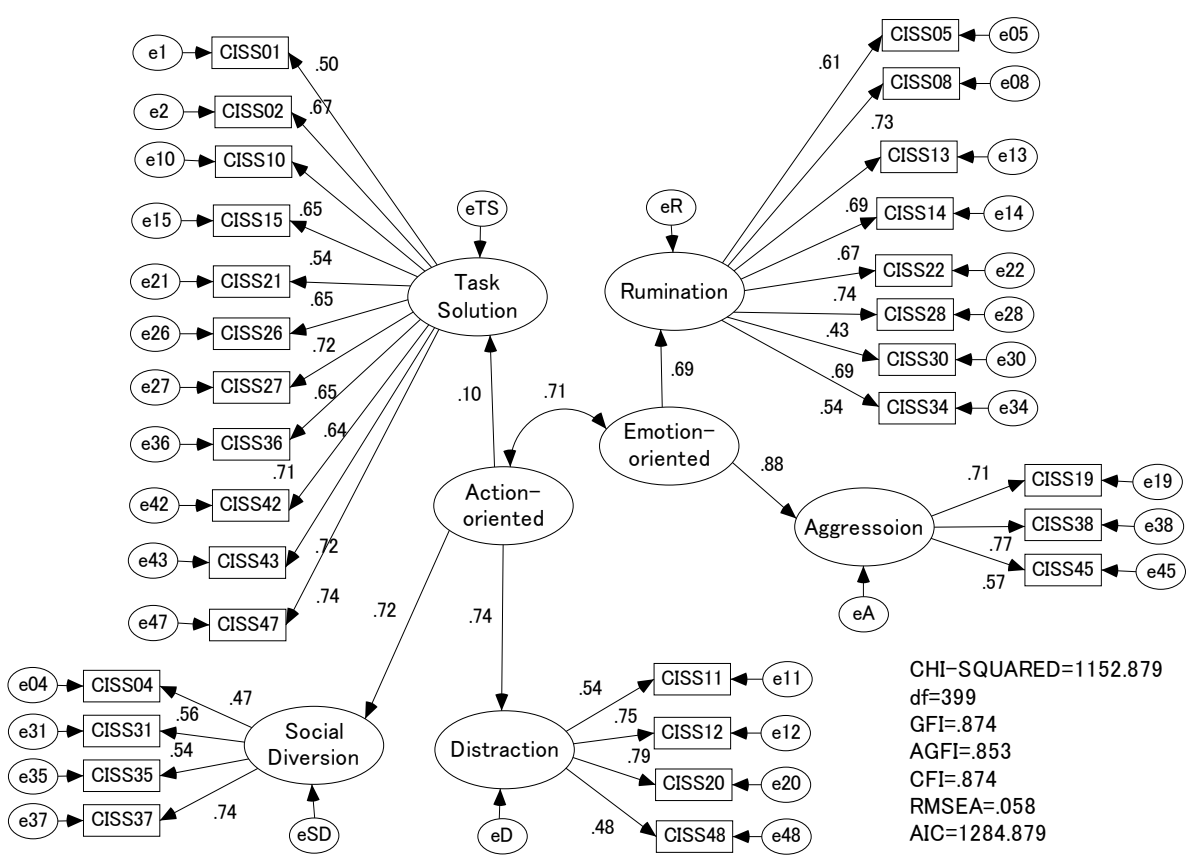

Figure 1. Confirmatory factor analysis of the five-factor model.

Table 1. Model fit statistics for factor structure of CISS.

\begin{tabular}{ccccccc}
\hline Model & $\mathrm{x}^{2}$ & GFI & AGFI & CFI & RMSEA & AIC \\
\hline Three-factor model (Endler \& Parker, 1990) & 1516.32 & .833 & .807 & .813 & .070 & 1642.32 \\
Four-factor model 1 (Endler \& Parker, 1994) & 1344.98 & .856 & .832 & .842 & .065 & 1474.98 \\
Four-factor model 2 (Cosway, Endler, Sadler, \& Deary, 2000) & 1344.98 & .856 & .832 & .842 & .065 & 1474.98 \\
Five-factor model (Sakata, Takagishi, \& Kitamura, 2013) & 1152.88 & .874 & .853 & .874 & .058 & 1284.88 \\
\hline
\end{tabular}

$x^{2}$ : chi-squared, GFI: goodness-of-fit index, AGFI: adjusted goodness-of-fit index, CFI: comparative fit index, RMSEA: root mean square error of approximation, and AIC: Akaike information criterion.

$<.001, \mathrm{t}(566)=-5.68, p<.001, \mathrm{t}(566)=-4.68, p<.001$, and $\mathrm{t}(566)=-1.14, p>.05$, respectively]. Better fit of the model for simultaneous multiple-group analysis between the men and women was shown in model 3 , in which the corresponding factor loadings, factor variances, and factor covariances were constrained across groups, than in model $1(\mathrm{GFI}=.835, \mathrm{AGFI}=.812, \mathrm{CFI}=.863, \mathrm{RMSEA}=.042$, $\mathrm{AIC}=1850.174$; and $\mathrm{GFI}=.832$, $\mathrm{AGFI}=.808, \mathrm{CFI}=.861, \mathrm{RMSEA}=.042$, $\mathrm{AIC}=1870.814$, respectively). Therefore, there was homogeneity within the same path diagram between the group of men and women also.

\subsection{Test-Retest Reliability}

Test-retest reliability was examined using time 1 data and time 2 data. The result shows significant correlation among corresponding items. Although all items were significantly correlated, a sex difference occurred in some items. Although, there were sex differences, the correlations were statistically significant between factors in time 1 and time 2 (Table 2). Women's mean scores were significantly higher than men's except on Task-Solution coping. Although sex differences among scores on some items and among factors, as simultaneous multiple-group analysis indicated, the model structure did not show significant sex difference.

\subsection{Predictive Validity}

All measured coping styles at time 1 were significantly correlated with symptoms except Task Solution coping and Somatization, Obsessive-Compulsiveness, and Interpersonal Sensitivity as shown in Table 3 and Table 4.

As Figure 2 and Table 5 show, the scores on Rumination at time 1 predicted all of the symptoms. Interpersonal Sensitivity, Depression, and Anxiety, the Task Solution time 1 also predicted their occurrence of them 
Table 2. Test-retest correlation coefficient of factor and means (and standard deviations) of time 1 by gender.

\begin{tabular}{ccccc}
\hline Factor & Correlation coefficient & Men $(\mathrm{n}=365)$ & Women $(\mathrm{n}=203)$ & $p$ \\
\hline Task Solution & $.61^{* *}$ & $33.21(6.59)$ & $31.82(6.26)$ & ${ }^{*}$ \\
Rumination & $.70^{* *}$ & $18.78(5.03)$ & $20.93(5.61)$ & $* .15(2.57)$ \\
Distraction & $.62^{* * *}$ & $7.01(2.54)$ & $13.07(3.83)$ & $* * *$ \\
Social Diversion & $.69^{* *}$ & $11.28(3.46)$ & $6.37(2.04)$ & \\
Aggression & $.63^{* * * *}$ & $6.16(2.06)$ & & \\
\hline
\end{tabular}

${ }^{*} p<.05,{ }^{* *} p<.01,{ }^{* * *} p<.001$.

Table 3. Intercorrelations of the variables used in this study time 1.

\begin{tabular}{|c|c|c|c|c|c|}
\hline & & & Time 1 & & \\
\hline & Task Solution & Distraction & Obsessive-Compulsiveness & Rumination & Aggression \\
\hline Somatization & -.02 & $.21^{* * *}$ & .08 & $.39^{* * *}$ & $.31^{* * * *}$ \\
\hline Obsessive-Compulsiveness time 1 & -.03 & $.26^{* * * *}$ & $.09^{*}$ & $.61^{* * *}$ & $.33^{* * *}$ \\
\hline Interpersonal Sensitivity time 1 & -.04 & $.27^{* * *}$ & .08 & $.56^{* * *}$ & $.42^{* * *}$ \\
\hline Anxiety time 1 & -.07 & $.27^{* * *}$ & $.11^{* *}$ & $.59^{* * *}$ & $.41^{* * *}$ \\
\hline Depression time 1 & -.07 & $.26^{* * *}$ & $.10^{*}$ & $.56^{* * *}$ & $.35^{* * *}$ \\
\hline Somatization time 2 & -.05 & $.20^{* * *}$ & $.09^{*}$ & $.39^{* * *}$ & $.28^{* * *}$ \\
\hline Obsessive-Compulsiveness time 2 & -.04 & $.25^{* * *}$ & $.11^{* *}$ & $.57^{* * *}$ & $.31^{* * *}$ \\
\hline Interpersonal Sensitivity time 2 & -.07 & $.25^{* * *}$ & $.09^{*}$ & $.53^{* * *}$ & $.37^{* * *}$ \\
\hline Anxiety time 2 & $-.13^{* *}$ & $.28^{* * * *}$ & $.13^{* *}$ & $.54^{* * *}$ & $.36^{* * *}$ \\
\hline Depression time 2 & $-.09^{*}$ & $.25^{* * *}$ & $.11^{* *}$ & $.54^{* * *}$ & $.32^{* * * *}$ \\
\hline
\end{tabular}

${ }^{*} p<.05,{ }^{* *} p<.01,{ }^{* * * *} p<.001$.

Table 4. Intercorrelations of the variables used in this study time 2.

\begin{tabular}{|c|c|c|c|c|c|}
\hline & \multicolumn{5}{|c|}{ Time 2} \\
\hline & Task Solution & Distraction & Obsessive-Compulsiveness & Rumination & Aggression \\
\hline Somatization & -.07 & $.16^{* * *}$ & .03 & $.29^{* * *}$ & $.30^{* * *}$ \\
\hline Obsessive-Compulsiveness time 1 & -.06 & $.26^{* * *}$ & .05 & $.50^{* * *}$ & $.33^{* * *}$ \\
\hline Interpersonal Sensitivity time 1 & -.08 & $.27^{* * *}$ & .05 & $.48^{* * *}$ & $.39^{* * *}$ \\
\hline Anxiety time 1 & $-.11^{*}$ & $.25^{* * *}$ & $.10^{*}$ & $.51^{* * *}$ & $.39^{* * * *}$ \\
\hline Depression time 1 & $-12^{* *}$ & $.26^{* * *}$ & $.09^{*}$ & $.47^{* * * *}$ & $.38^{* * * *}$ \\
\hline Somatization time 2 & $-.14^{* *}$ & $.19^{* * *}$ & .06 & $.36^{* * *}$ & $.31^{* * * *}$ \\
\hline Obsessive-Compulsiveness time 2 & $-.13^{* *}$ & $.25^{* * *}$ & .07 & $.56^{* * *}$ & $.32^{* * * *}$ \\
\hline Interpersonal Sensitivity time 2 & $-.15^{* * *}$ & $.29^{* * *}$ & .05 & $.55^{* * *}$ & $.40^{* * * *}$ \\
\hline Anxiety time 2 & $-.22^{* * *}$ & $.26^{* * *}$ & $.12^{* *}$ & $.54^{* * * *}$ & $.39^{* * *}$ \\
\hline Depression time 2 & $-.19^{* * *}$ & $.29^{* * *}$ & $.09^{*}$ & $.56^{* * * *}$ & $.38^{* * *}$ \\
\hline
\end{tabular}

${ }^{*} p<.05,{ }^{* *} p<.01,{ }^{* * *} p<.001$.

Table 5. Path coefficients on the predictive model.

\begin{tabular}{|c|c|c|c|c|c|c|}
\hline & Path a & Path & Path c & Path d & Path e & Path $\mathrm{f}$ \\
\hline Somatization & $.68^{* * *}$ & -.05 & .01 & .01 & $.12^{* *}$ & .00 \\
\hline Obsessive-Compulsiveness & $.63^{* * *}$ & -.04 & .01 & .01 & $.18^{* *}$ & .01 \\
\hline Interpersonal Sensitivity & $.67^{* * *}$ & $-.06^{*}$ & .00 & .01 & $.15^{* *}$ & .02 \\
\hline Depression & $.62^{* * *}$ & $-.06^{*}$ & .01 & .01 & $.19^{* *}$ & .01 \\
\hline Anxiety & $.61^{* * *}$ & -.11 & .03 & .03 & $.16^{* *}$ & .01 \\
\hline
\end{tabular}

${ }^{*} p<.05,{ }^{* *} p<.01,{ }^{* * *} p<.001$. 


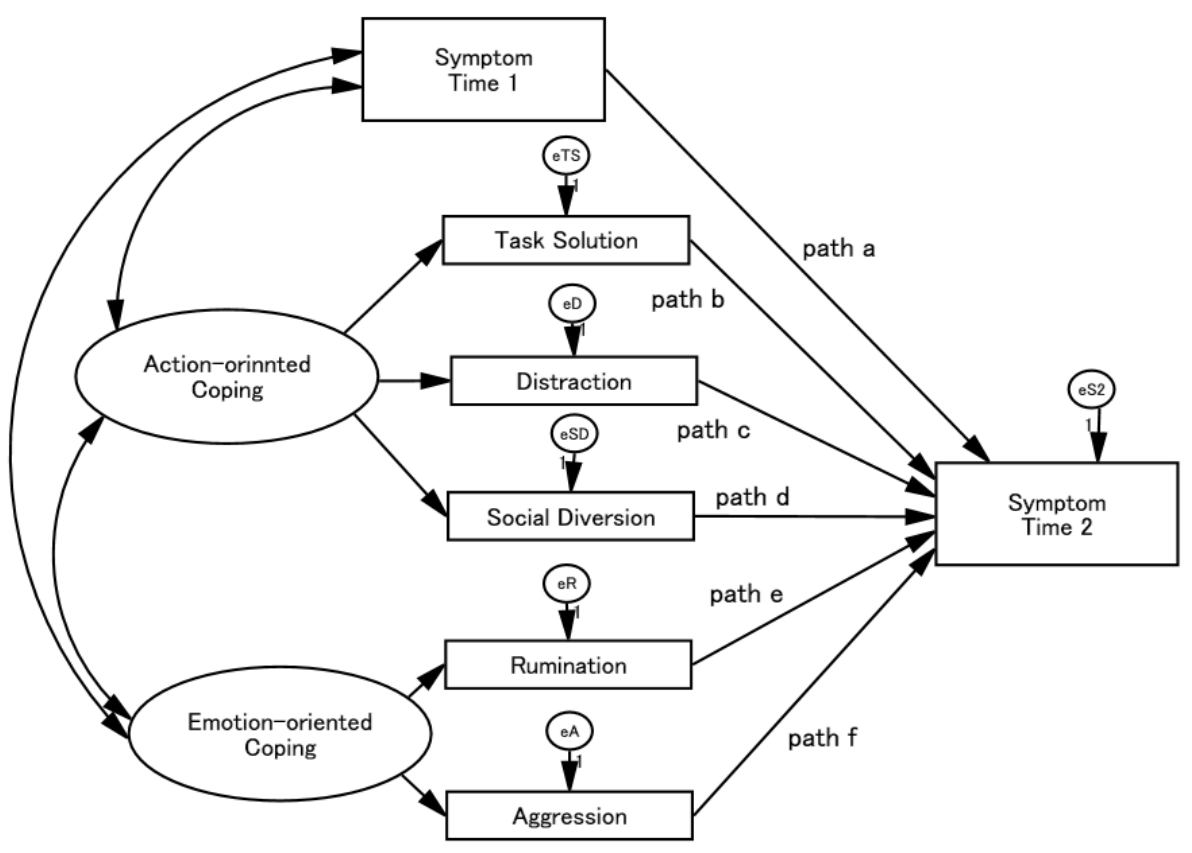

Figure 2. Predictive model of coping styles and symptom.

negatively.

\section{Discussion}

This study aimed to first evaluate whether the five-factor model of the CISS (Sakata et al., 2013) can be applicable for not only students but also workers. Analyses confirmed the five-factor model has the best fit among the three-, four-, and five-factor models of the CISS. In terms of sex difference, women tended to score higher than men on all factors except the Task scale; this was consistent with previous studies (Endler \& Parker, 1990, 1994; Cosway et al., 2000). However, the overall factor structure of the CISS was not different for men and women, which means that the five-factor model has a robust structured scale.

On the other hand, suggested by prospective analysis, coping strategies were related to stress symptoms, Rumination especially led to all of symptoms. Rumination as coping is composed elements that represent repetitive and passive ways of thinking about one's negative emotions (e.g., "Worry about next step", "Blame myself for not having a solution") in the CISS. Several researchers have shown that ruminative behavior is associated with depressive symptoms (Ito, Tomita, Hasui, Otsuka, Katayama, Kawamura et al., 2003; Nolen-Hoeksema, Paeker, \& Larson, 1994; Nolen-Hoeksema, Girgus, \& Seligman, 1992). Additionally, in some recent studies, the ruminative response style was also associated with anxiety symptoms (Fresco, Frankel, Mennin, Turk, \& Heimberg, 2002; Nolen-Hoeksema, 2000). In the present results, rumination predicts Somatization, Obsessive-Compulsiveness, Interpersonal Sensitivity, Depression, and Anxiety. Because rumination leads to psychological maladjustment various different symptoms, it is possible that areas being ruminated raise various issues. For example, one could dwell on past failure, future, relations with a friend, and one's health. These are related to depression, anxiety, interpersonal sensitivity, and somatization, respectively. Therefore, one may conclude that to ruminate for a short period of time on past events, current issues, and anxiety about the future may be a good way to keep good health. This suggestion applies broadly, as the results of this study support the one of other studies (Nolen-Hoeksema, 2000; Nolen-Hoeksema, Paeker, \& Larson, 1994) that women tend to use ruminative coping more than men. However, when people who ruminate to solve their problems come up with solutions, the quality of their solutions is lower than that of people who do not (Lyubomirsky \& Nolen-Hoeksema, 1995). Psychoeducation regarding appropriate targets for rumination could be helpful for people who tend to ruminate pessimistically.

Findings from this study clearly indicate that the five-factor model of the CISS provides an appropriate and useful structure for not only statistical findings but also clinical application. However, there are two limitations 
which prevent any generalizability of these findings until additional research has been conducted. First, it would be more useful to clarify which coping strategies are used most effectively in given stressful situations. Second, the sample was a general population; therefore, applying the CISS five-factor model in a clinical population would be informative.

\section{References}

Cosway, R., Endler, N. S., Sadler, A. J., \& Deary, I. J. (2000). The Coping Inventory for Stressful Situations: Factorial Structure and Associations with Personality Traits and Psychological Health. Journal of Applied Biobehavioral Research, 5, 121-143. http://dx.doi.org/10.1111/j.1751-9861.2000.tb00069.x

Derogatis, L. R., Lipman, R. S., Rickels, K., Uhlenhuth, E. H., \& Covi, L. (1974). The Hopkins Symptom Checklist (HSCL): A Self-Report Symptom Inventory. Behavioral Science, 19, 1-15. http://dx.doi.org/10.1002/bs.3830190102

Endler, N. S., \& Parker, J. D. A. (1990). Multidimensional Assessment of Coping: A Critical Evaluation. Journal of Personality and Social Psychology, 58, 844-854. http://dx.doi.org/10.1037/0022-3514.58.5.844

Endler, N. S., \& Parker, J. D. A. (1994). Assessment of Multidimensional Coping: Task, Emotions, and Avoidance Strategies. Psychological Assessment, 6, 50-60. http://dx.doi.org/10.1037/1040-3590.6.1.50

Endler, N. S., Parker, J. D. A., \& Butcher, J. N. (1993). A Factor Analytic Study of Coping Styles and the MMPI-2 Content Scales. Journal of Clinical Psychology, 49, 523-527. http://dx.doi.org/10.1002/1097-4679(199307)49:4<523::AID-JCLP2270490409>3.0.CO;2-M

Folkman, S., \& Lazarus, R. S. (1985). If It Changes It Must Be a Process: A Study of Emotion and Coping during Three Stages of a College Examination. Journal of Personality and Social Psychology, 48, 150-170.

http://dx.doi.org/10.1037/0022-3514.48.1.150

Folkman, S., \& Lazarus, R. S. (1988). Manual for the Ways of Coping Questionnaire: Research Edition. Palo Alto, CA: Consulting Psychologists Press.

Fresco, D. M., Frankel, A. N., Mennin, D. S., Turk, C. L., \& Heimberg, R. G. (2002). Distinct and Overlapping Features of Rumination and Worry: The Relationship of Cognitive Production to Negative Affective States. Cognitive Therapy and Research, 26, 179-188. http://dx.doi.org/10.1023/A:1014517718949

Higgins, J. E., \& Endler, N. S. (1995). Coping, Life Stress, and Psychological and Somatic Distress. European Journal of Personality, 9, 253-270. http://dx.doi.org/10.1002/per.2410090403

Ito, T., Tomita, T., Hasui, C., Otsuka, A., Katayama, Y., Kawamura, Y. et al. (2003). The Link between Response Styles and Major Depression and Anxiety Disorders after Child-Loss. Comprehensive Psychiatry, 44, 396-403. http://dx.doi.org/10.1016/S0010-440X(03)00109-3

Lazarus, R. S. (1999). Stress and Emotion: A New Synthesis. New York: Springer.

Lazarus, R. S., \& Folkman, S. (1984). Stress, Appraisal, and Coping. New York: Springer.

Lyubomirsky, S., \& Nolen-Hoeksema, S. (1995). Effects of Self-Focused Rumination on Negative Thinking and Interpersonal Problem Solving. Journal of Personality and Social Psychology, 69, 176-190. http://dx.doi.org/10.1037/0022-3514.69.1.176

McWilliams, L. A., Cox, B. J., \& Enns, M. W. (2003). Use of the Coping Inventory for Stressful Situations in a Clinically Depressed Sample: Factor Structure, Personality Correlates, and Prediction of Distress. Journal of Clinical Psychology, 59, 1371-1385. http://dx.doi.org/10.1002/jclp.10228

Moos, R. H., \& Holahan, C. J. (2003). Dispositional and Contextual Perspectives on Coping: Toward an Integrative Framework. Journal of Clinical Psychology, 59, 1387-1403. http://dx.doi.org/10.1002/jclp.10229

Nakano, K., \& Kitamura, T. (2001). The Relation of the Anger Subcomponent of Type A Behavior to Psychological Symptoms in Japanese and Foreign Students. Japanese Psychological Research, 43, 50-54. http://dx.doi.org/10.1111/1468-5884.00159

Nolen-Hoeksema, S. (2000). The Role of Rumination in Depressive Disorders and Mixed Anxiety/Depressive Symptoms. Journal of Abnormal Psychology, 109, 504-511. http://dx.doi.org/10.1037/0021-843X.109.3.504

Nolen-Hoeksema, S., Girgus, J. S., \& Seligman, M. E. (1992). Predictors and Consequences of Childhood Depressive Symptoms: A 5-Year Longitudinal Study. Journal of Abnormal Psychology, 101, 405-422. http://dx.doi.org/10.1037/0021-843X.101.3.405

Nolen-Hoeksema, S., Paeker, L. E., \& Larson, J. (1994). Ruminative Coping with Depressed Mood Following Loss. Journal of Personality and Social Psychology, 67, 92-104. http://dx.doi.org/10.1037/0022-3514.67.1.92

Rafnsson, F. D., Smari, J., Windle, M., Mears, S. A., \& Endler, N. S. (2006). Factor Structure and Psychometric Characteristics of the Icelandic Version of the Coping Inventory for Stressful Situations (CISS). Personality and Individual Differ- 
ences, 40, 1247-1258. http://dx.doi.org/10.1016/j.paid.2005.11.011

Sakata, M., Takagishi, Y., \& Kitamura, T. (2013). Factor Structure and Psychometric Properties of the Japanese Version of the Coping Inventory for Stressful Situations (CISS): A Reclassification of Coping Styles Using both Exploratory and Confirmatory Factor Analyses. Journal of Psychology and Psychotherapy, 3, 2.

Schermelleh-Engel, K., Moosbrugger, H., \& Müller, H. (2003). Evaluating the Fit of Structural Equation Models: Test of Significance and Descriptive Goodness-of-Fit Measures. Methods of Psychological Research Online, 8, $23-74$.

Skinner, E. A., Edge, K., Altman, J., \& Sherwood, H. (2003). Searching for the Structure of Coping: A Review and Critique of Category Systems for Classifying Ways of Coping. Psychological Bulletin, 129, 216-269. http://dx.doi.org/10.1037/0033-2909.129.2.216

Van Heck, G., \& De Ridder, D. (2001). Dimensions and Measurement of Coping with Loss. In M. S. Stroebe, W. Stroebe, R. O. Hansson, \& H. Schut (Eds.), New Handbook of Bereavement: Consequences, Coping, and Care (pp. 449-469). Washington, DC: American Psychological Association. 
Scientific Research Publishing (SCIRP) is one of the largest Open Access journal publishers. It is currently publishing more than 200 open access, online, peer-reviewed journals covering a wide range of academic disciplines. SCIRP serves the worldwide academic communities and contributes to the progress and application of science with its publication.

Other selected journals from SCIRP are listed as below. Submit your manuscript to us via either submit@scirp.org or Online Submission Portal.
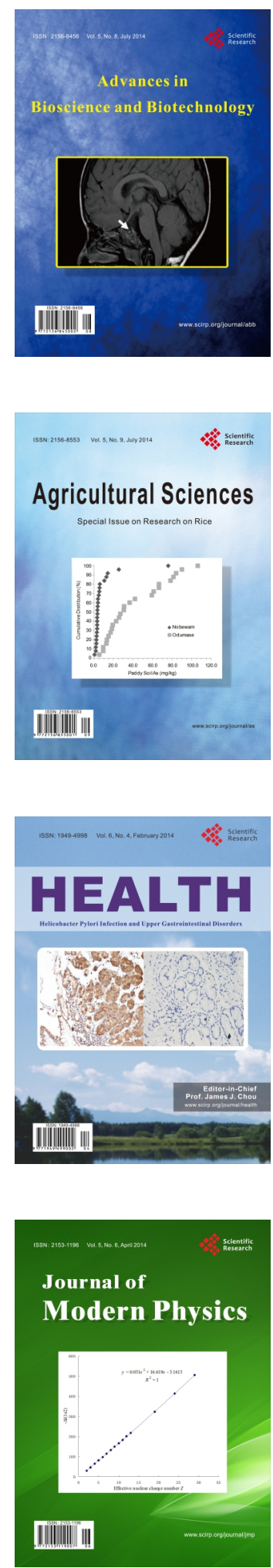
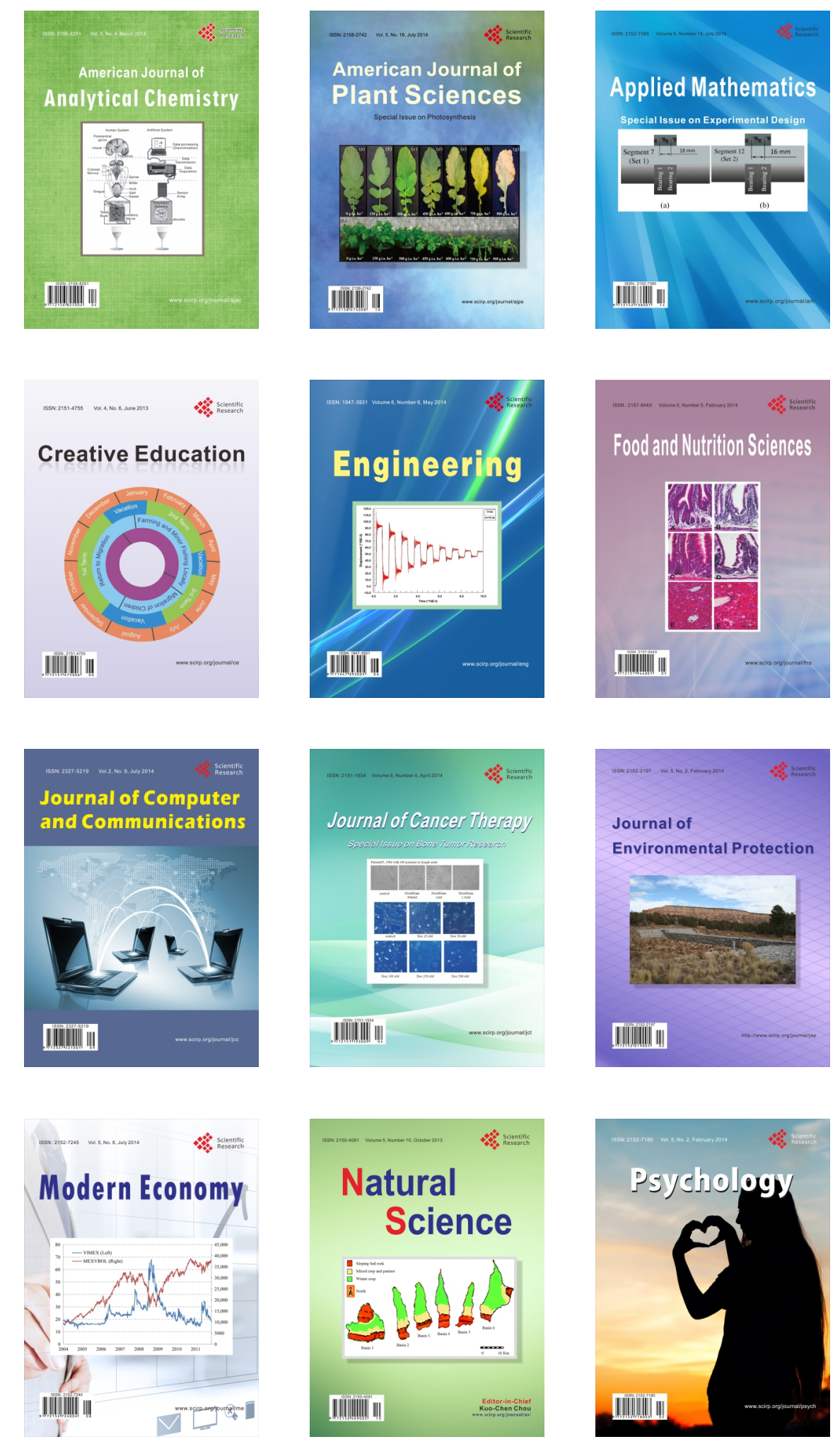